\title{
CORRECTION
}

Check for updates

Cite this: J. Mater. Chem. A, 2018, 6, 13975

Received 28th June 2018

Accepted 28th June 2018

DOI: $10.1039 / \mathrm{c} 8 \operatorname{ta} 90157 \mathrm{k}$

www.rsc.org/MaterialsA

\section{Correction: Interface-engineered hematite nanocones as binder-free electrodes for high- performance lithium-ion batteries}

\author{
Lei Wang, ${ }^{a}$ Kun Liang, ${ }^{\mathrm{b}}$ Guanzhi Wang ${ }^{\mathrm{b}}$ and Yang Yang*b \\ Correction for 'Interface-engineered hematite nanocones as binder-free electrodes for high-performance \\ lithium-ion batteries' by Lei Wang et al., J. Mater. Chem. A, 2018, DOI: 10.1039/c8ta03106a.
}

In the original manuscript, the SEM images used in the table of contents image, Fig. $1 \mathrm{f}$ and the insets of Fig. $1 \mathrm{~d}$ and $\mathrm{f}$ were incorrect and were not clearly labelled. Correct versions of the figures are given below.

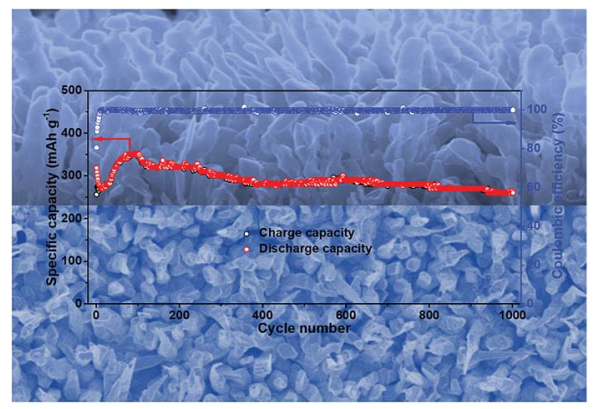

Table of Contents image

\footnotetext{
${ }^{a}$ State Key Laboratory for Oxo Synthesis and Selective Oxidation, National Engineering Research Center for Fine Petrochemical Intermediates, Lanzhou Institute of Chemical Physics, Chinese Academy of Sciences, 730000 Lanzhou, China

${ }^{b}$ NanoScience Technology Center, Department of Materials Science \& Engineering, University of Central Florida, 4000 Central Florida Blvd, Orlando, Florida, 32816, USA. E-mail: Yang.Yang@ucf.edu
} 



Fig. 1 (a) Schematic illustration of the fabrication of $\mathrm{Fe}_{2} \mathrm{O}_{3} \mathrm{NCs}$. (b) XRD patterns of $\mathrm{Au} / \mathrm{Fe}, \mathrm{Fe}_{2} \mathrm{O}_{3} \mathrm{NFs}$, and $\mathrm{Fe}_{2} \mathrm{O}_{3} \mathrm{NC}$ samples. (c-f) Top and

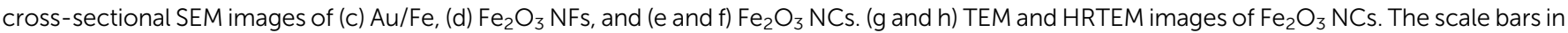
the insets of ( $d$ and $f$ ) denote $1 \mu \mathrm{m}$.

The Royal Society of Chemistry apologises for these errors and any consequent inconvenience to authors and readers. 